\title{
The Effect of Auditory Hallucinations Management Program on Quality of Life For Schizophrenic Inpatients, Egypt
}

\author{
Eman S. Abd ELhay ${ }^{1}$, Mona A. El-Bilsha ${ }^{1}$, Mohamed H. El-Atroni ${ }^{2}$ \\ ${ }^{1}$ Psychiatric Nursing and Mental Health, Mansoura University, Faculty of Nursing, Egypt \\ ${ }^{2}$ Psychiatry Medicine, Faculty of Medicine, Mansoura University, Egypt
}

\begin{abstract}
Auditory hallucinations are pervasive in people with schizophrenia. Despite high doses of medication a significant number of patients still experience distressing auditory hallucinations. Furthermore, schizophrenic patients who had persistent distressing voices use dangerous techniques as a way for managing auditory hallucinations. This study aimed to determine the effect of the auditory hallucinations management program on quality of life for schizophrenic inpatients. A quasi-experimental design was used. The subjects of this study comprised 100 hospitalized schizophrenic patients (50 and 50 male and female, schizophrenic patients were recruited from inpatient wards of El-Maamoura hospital for Psychiatric Medicine in Alexandria, Egypt. Data was collected by using the following tools: Tool I: Characteristics of Auditory Hallucinations Rating Scale. Tool II: The Schizophrenia Quality Of Life Scale. Results: The findings documented that auditory hallucination management program led to improve patient's quality of life, it was demonstrated to be effective in reducing the severity level of auditory hallucinations in patients with schizophrenia. There was a significant positive correlation between total schizophrenia quality of life and severity of auditory hallucinations. Implications for further studies are needed to evaluate the effectiveness of long-term follow up of auditory hallucinations symptom management program on the schizophrenic quality of life are suggested.
\end{abstract}

Keywords: Auditory Hallucinations, Management program, Quality of Life. Schizophrenia.

\section{Introduction}

Schizophrenia is considered a chronic disorder with poor outcomes and considered one of the major psychotic illnesses in Egypt. According to the National Institute of Mental Health (NIMH, 2011), schizophrenia is relatively common, affecting $1.1 \%$ of the population and/or around 65 million people worldwide suffer from schizophrenia [1].

Hallucination is one of the main positive symptoms of schizophrenia [2]. It is estimated that $90 \%$ of the patients with schizophrenia experience hallucinations [3]. Seventy five percentages of schizophrenic patients usually have auditory hallucinations[4]. Auditory hallucinations are pervasive in people with schizophrenia. Despite high doses of medication a significant number (25\%-50\%) of patients with schizophrenia still experience distressing auditory hallucinations and it is becoming persistent symptomatic. However, long-term use of the medications may cause side effects, such as weight gain, decreased libido, and restlessness [5 \& 6].

In Egypt, a descriptive study was done by Abd Elhay (2008), stated that $77 \%$ of the studied schizophrenic patients reacting to auditory hallucination with anger, and feeling of fear and anxiety toward the voices. Furthermore, $91 \%$ of the studied schizophrenic patients use dangerous techniques such as "hurt the self" and "do as the voices say" as a way for managing auditory hallucinations. The heard voices were often regarded as dangerous because "voices" tell patients to commit murder and/ or to harm themselves. Some patients, burn themselves just to obey the persistent and distressing voices, to stop it [7].

Persistent auditory hallucinations produce negative adverse effects, including heightened anxiety, depression, social withdrawal, homicide, suicide, and affect the quality of patients' lives [8]. Schizophrenic patients who have auditory hallucinations suffer from distress, disability, reduced productivity and then their quality of life were affected [9].

Quality of life is a dynamic concept that can change from day to day and is characterized by its individuality; each person perceives his or her QoL as different from that of others' [10]. Poor quality of life has been found to be linked to a subjective appreciation of the voices rather than to their sole presence [11]. Persistent auditory hallucinations can affect the quality of life, and can impair engaging in activities requiring sustained concentration and attention [12].

A model for symptom management has defined symptoms as subjective experiences reflecting changes in a person's biopsychosocial function, sensation, and/ or cognition [13]. According to Kanungpairn, Sitthimongkol, Wattanapailin, and Klainin (2007) the process of auditory hallucination management is a systematic process consisting of auditory hallucination management experience, strategies, and outcome [14]. The symptom management model includes three interrelated dimensions: (a) symptom experience; (b) symptom 
management strategies provided by the patient, family, health care providers, and the health care system; and (c) symptom outcomes [13].

Auditory hallucination symptom experience is the first dimension which refers to patients' experience of various symptoms, deriving from their perception, definition, and reaction to the symptoms. Auditory hallucination management strategies are dynamic process, or constant changes. It is believed that every symptom has its meaning and requires constant management. The goal of management is to reduce the severity of symptoms and negative adverse effects. In addition, symptom management depends on patients' acceptance of having the symptom and their cooperation in the management of voices. The auditory hallucination management outcome is the result from the utilization of the strategies [15-20].

The auditory hallucinations management program was started from the patient's evaluation of symptom experience along with the analysis of purpose, changes, process, and outcome of practice. Auditory hallucination management strategy is a dynamic process, constantly changing with the times and the patient's perception. Symptom management strategies involve the method, duration, place, reason, and volume of management, including the target person and how they can be conducted [21].

On the other hand, the model of auditory hallucination management focuses on the promotion of systematic auditory hallucination self-management, using past experience to choose successful strategies that are effective and uncomplicated for the management of auditory hallucination [14]. Nurses have a significant role as the person responsible for promoting patients' effective symptom management. They collaboratively develop guidelines for managing various symptoms, including symptoms that require long-term management.

Aim of the study:

This study aimed to investigate the effect of auditory hallucinations management program on quality of life among patients with schizophrenia.

\section{Research questions:}

- Does the auditory hallucination management program will demonstrate a reduction in the severity level of auditory hallucination at the end of the program in comparison with the symptom before the program?

- Does the auditory hallucination management program will improve the quality of life for schizophrenic patients who participate in the program?

- What is the relation between auditory hallucinations and quality of life among schizophrenic patients?

\section{Subjects And Methods}

Study design: A quasi- experimental design was used to conduct this study.

Setting: The study was conducted at El-Maamoura Hospital for Psychiatric Medicine, in Alexandria. The hospital is affiliated to the ministry of health. The present study was conducted in all gratis and paid male and female wards.

Subjects: The subjects of this study comprised 100 hospitalized schizophrenic patients. They were distributed into two groups, a study and comparative group (50 and 50 male and female schizophrenic patients respectively).

The subjects of both groups had been selected according to the following criteria:-

1. Patients fulfilling criteria for schizophrenia and acknowledged the presence of auditory hallucinations.

2. Adult aged between 18 up to 55 years.

3. Patients of either sex.

4. Patients who willing to participate in the auditory hallucinations management program to manage their auditory hallucinations.

5. Exclusion criteria are: Schizoaffective patients, Patients who receiving electroconvulsive therapy or who consumed illegal drugs, and Patients who are uncooperative or with incoherent speech were excluded from the study.

Tools of the study:

Data was collected by using the following tools:

Tool (I): Characteristics Of Auditory Hallucinations Rating Scale. The scale was originally developed by (Oulis et al, 2007). The scale measures various parameters of hallucination. It consists of 18 items, each of which is scored from one to three; one is the lowest severity while three indicate the highest severity. The hallucination severity score therefore ranged from 18 to 54 [22].

Tool (II): The Schizophrenia Quality Of Life Scale Revision 4 (SQLS-R4). The scale was originally developed by (Wilkinson et al, 2000) and the modified version of the schizophrenia quality of life scale available on published thesis (Kuo et al, 2007). SQLS-R4 had good internal consistency, good test-retest reliability, and acceptable convergent validity. The scale measure quality of life for schizophrenic patients. The 
psychometric properties and the domain structure of SQLS-R4 are well defined and have been submitted for publication. The total 33 items are divided into two domains: Psychosocial consists of 20 items, and vitality consists of 13 items. In the coding system, 0 stands for "never", 1 "rarely", 2 "sometimes", 3 "often", and 4 "always". Some items in this scale ask whether patients engage in positive aspects of life, these four items are $(7,12,14$, and 26$)$ in the vitality domain need to be coded in reverse direction and are recoded $4=0,3=1,2=$ $2,1=3$, and $0=4$ before the scale total is calculated [9 \&23].

In addition to socio-demographic and clinical data structured interview schedule: It was developed by the researcher to elicit data about the studied subjects.

\section{Administrative steps}

- An official permission to conduct the study was obtained from the postgraduate committee, as well as the ethical committee, Faculty of Nursing; Mansoura University.

- An official permission to conduct the study was obtained from the Human Rights Protection Committee of the General Secretariat for Mental Health, Ministry of Health and Population, in Cairo.

- The official approval was obtained from the hospital's director of the El-Maamoura Hospital for Psychiatric Medicine, in Alexandria before starting the study.

\section{Preparation of the study tools}

The socio-demographic and clinical data tool was developed by the researcher. The tools I and II were translated into Arabic language; and tested for content validity by a jury of 5 experts in the field of psychiatric nursing and mental health. The tool I and tool II were tested for its reliability using Alpha Cronbach's $(\infty=93.3$ and 90.2) on 20 patients with schizophrenia using a test-retest method with a time period of two weeks in between each one of them. They were excluded from the study subjects.

\section{Pilot study}

A pilot study was carried out on 10 schizophrenic patients selected randomly in order to ascertain the clarity and applicability of the study tools, to identify any obstacle in applying these tools, and to estimate the time required for interviewing the patients. The results of pilot study revealed that the tools were clear and applicable. These subjects were excluded from the actual study.

\section{Ethical issues}

The aim of the program was explained to subjects prior to seeking their participation in the study. Patient's written consent to participate in the study was then obtained. For those who were illiterate, the informed was read to them and then give oral consent. They were given an opportunity to refuse to participate in the study. They were notified that they could withdraw at any stage of the research study and that don't affect their grades. Finally, they were assured that The study data are kept confidential and will be used for the research purpose only.

\section{Actual study}

The actual study was conducted during the period from August 2014 to March 2015. It went through three phases:

\section{Phase I: Selection of the subjects}

- Random selection of the hospital wards was done using simple randomization by picking their names up from a pool. On the first prioritized ward, all patients' charts were reviewed to identify those who meet the study criteria. Those who met these criteria were met on an individual base in order to establish a relationship with them, explain the purpose of the study, provide brief and simple explanation about the training program, reassure the patients that all information would be confidential and used only for the purpose of the study. The informed consent of the patients to participate in the study was also ensured. Each interview lasted for 50-60 minutes.

- Each patient was assigned randomly to one of the two groups (experimental and comparative groups), 50 patients per each, and were exposed to the pre-testing using tools I, II, and the socio-demographic and clinical data tool. This was done in 2 sessions.

- The comparison group was exposed to the pre-testing using tools I, II, and the socio-demographic and clinical data tool and were received standard care and usual hospital services.

- The experimental group was divided into 8 groups; 6-7 patients per each group were attending the auditory hallucinations management program. 


\section{Phase II: Implementation of the auditory hallucination management program}

This phase is directed toward the implementation of the auditory hallucination management program for schizophrenic patients who have auditory hallucinations after reviewing related literature (Buffum, et al 2014;

Buccheri et al., 2013; Trygstad et al., 2010; Chen et al., 2009; Buccheri et al., 2009). [15-20]

- Sessions of auditory hallucination management training programs were conducted for a period 60-90 minutes a session, every day for a period of 8 weeks. In some instances, sessions were carried out twice per week instead of 1 session per week, because of patients' shortened length of hospitalization and the very high patients turn over.

- Before each session, the environment should be comfortable and the patients were well prepared. The environment was almost cute, well ventilated, and well cleaned. A comfortable chair was used, and was arranged in a circular shape. At the first session, the researcher met the patients in a quiet room (the dining room and doctors' room), greeted them, allowed the patients to take their seats and introduced him/ herself to them as well as each patient to the others and then provided detailed information to them in relation to:

a) Number of the group members, place of meeting, duration of the program, frequency of meetings and length of each session.

b) Clarification of the objectives and the specific goals of the program.

c) Grounded rules of the group, e.g. confidentiality and honesty. What to expect from the group in terms of their own roles, e.g. Listen attentively to each other, there are no right or wrong answers, and everyone has an equal chance to participate.

d) A homework assignment that would be given at the end of each session.

- Throughout the training of auditory hallucinations management program, the researcher used brain storming to encourage wide and creative thinking about the topic of the sessions. This was done through stating strategies to the group, listening to their experience of auditory hallucinations and recording it on the white board. The 10-session auditory hallucination management program was developed based on an extensive literature review of strategies to manage auditory hallucinations [15-20]. The sessions of the program are as follows:

Session 1: Establishing relationship, gathering information about the patients, and providing knowledge about psychotic symptoms and the auditory hallucination management program.

Session 2: Examining the patients' experience of auditory hallucination and providing knowledge about auditory hallucination.

Session3: Examining the patients' quality of life. The session focus on the participant's experience related to quality of life.

Session 4: Self-monitoring as a management strategy for auditory hallucination.

Session 5: "Talking with others" technique to manage auditory hallucination.

Session 6: Demanding "STOP" or ignoring/ not following the voices.

Session 7: Sub-vocally repeat short sentences and read aloud.

Session 8: Singing or humming to manage auditory hallucination.

Session 9: Using relaxation techniques such as breathing exercise to manage auditory hallucination.

Session 10: Evaluation of the auditory hallucination management outcome. The researcher was encouraged participants to express their opinion about the strategies was learned and used in the training program, and terminate the group.

- In each session, we had started with reviewing homework assignment of previous skill and positive reinforcement was provided for patients' effort (consumable reinforces with what a person likes to eat or soft drink as sweets and chips). This consumed about ten to fifteen minutes. The rest of the time was consumed in the description of the session's objectives, explaining the rationale for its importance, and discussing with the patients specific steps to learn this skill.

\section{Phase 3}

Immediately and two months after the program completion, the post test was done for the study group after conducting ten sessions of the auditory hallucination management program through applying study tools on each patient on an individual base. This was done to overcome the possible drop out of these patients during conduction of the program. As for the comparison group a post test was done after a matched number of days compared to the study group. After conduction of the program nine patients were discharged.

\section{Statistical analysis:}

Data was fed, coded, edited and analyzed using the PC with Statistical Packages for Social Science (SPSS 17) and Windows Version 8.0. The selected level of significance was at $p \leq 0.05$. Descriptive statistics were done using numbers, percentage, arithmetic mean and standard deviation. The Pearson statistical test was 
The Effect of Auditory Hallucinations Management Program on Quality of Life For Schizophrenic ..

used to quantify the strength of the association between the study variables. Also, Student t-test was used to determine the difference between two groups.

\section{Results}

Table (1): It appears from the table that female and male patients represented an equal percentage in two groups. Also, it was shown that two third $(62 \%$ and $60 \%)$ of the study and comparative group were in the age group ranging from 25 to less than 45 years of age, (44\%) of the study and (50\%) comparative group patients had a preparatory school degree, (38\%) of the study group were worker compared to (52\%) of the comparison group were unemployed.

As for patients' marital status, $(60 \%$ and $64 \%)$ of the study and the comparative group reported they are single, $(96 \%)$ of the study and $(80 \%)$ of the comparative group patients were living with their families In addition, there were statistical significant differences regarding living conditions between the two groups $(\mathrm{P}=0$. 035).

Table (2): in relation to the patient's ages at onset of disease, (42\%) of the study group patients and (44\%) of the comparative group were from 20 to less than 25 years, Regarding the number of hospital admissions, (72\%) of the study and comparative group patients were admitted 4 times and more, $(76 \%)$ of the study group, and (58\%) of the control group were staying in the hospital for less than 3 months. Concerning the onset of auditory hallucination, $(72 \%)$ of the study group and $(86 \%)$ of the control group patients started to hallucinate since 10 years/ more.

Concerning the patient's reaction to auditory hallucinations, around two third (64\%) of the study group was feeling helpless and upset / sad and (62\%) of the control group were feeling upset / sad, while one third $(34 \%)$ of them were feeling fear, with no statistical significant differences between the two groups regarding reaction toward auditory hallucinations except angry reaction $(\mathrm{P}=0.002)$.

Table (3): present the severity level and the mean scores of auditory hallucinations among the studied schizophrenic patients. It was observed that, $(90 \%)$ and $(86 \%)$ of the study and comparative group were having severe auditory hallucinations respectively, with mean scores $(44.26 \pm 5.33 \& 43.22 \pm 6.03)$ in pre program implementation.

Immediately post, the severity level of auditory hallucinations was decreased to moderate level for (75.6\%) of the study group compared to $(64.3 \%)$ for the comparative group still had severe auditory hallucinations and the mean scores for them $(33.93 \pm 3.46 \& 39.14 \pm 5.42)$ respectively compared to pre-program. While after two months the program, the level of severity increased for $(80.5 \%)$ and $(71.8 \%)$ of the study and control group respectively. The mean scores of the study group are slightly increased compared to immediately post program $(38.49 \pm 3.70)$. Moreover, there were statistical significant difference was found between the study and comparative group in after the program 1 week $(\mathrm{P}=0.0001)$.

Table (4): illustrate the mean scores of schizophrenia quality of life domains (psychosocial / vitality domain) and total SQoL among the studied schizophrenic patients. It was observed that the mean scores and standard deviation of the SQoL psychosocial domain of study and comparative group were (14.48 \pm 1.85$) \&$ $(14.28 \pm 2.62)$ the table also revealed that SQOL vitality domain means scores of the study and comparative group were $(8.87 \pm 1.04) \&(8.85 \pm 1.16)$ at the pre-program implementation respectively.

Immediately post program, SQoL psychosocial domain of study and comparative group decreased compared to pre program were $(12.31 \pm 1.35) \&(13.81 \pm 2.25)$ the table also revealed that SQoL vitality domain mean scores of study and comparative group decreased compared to pre program were $(8.48 \pm 0.80) \&$ $(8.85 \pm 0.93)$ respectively. Two months after the program, SQoL psychosocial domain of study and control group slightly increased compared to immediately post program were $(12.75 \pm 1.14) \&(13.91 \pm 2.43)$ the table also revealed that SQoL vitality domain mean scores of study and control group slightly increased compared to immediately post program were $(8.84 \pm 0.87) \&(8.69 \pm 0.99)$ respectively.

The total mean scores of SQoL among the studied schizophrenic patients were $(23.36 \pm 2.37)$ and $(23.13 \pm 3.47)$ for the control group in pre program. Immediately post program, SQOL of the studied patients were decreased to $(20.79 \pm 1.77)$ compared to pre program and in the comparative group were decreased to $(22.40 \pm 2.87)$ compared to pre-program. Two months after the program, SQoL of the study group was slightly increased to $(21.60 \pm 1.60)$ compared to immediately post the program and in the control group the mean scores were slightly increased to $(22.60 \pm 3.05)$ compared to immediately post program. The decrease is statistically higher in the study than the comparative group, which means that is there highly statistically significant difference between study and comparative group regarding SQoL mean scores $(\mathrm{P}=0.0001)$.

Table (6): Presents the correlation between levels of total schizophrenia quality of life and severity of auditory hallucinations among the studied schizophrenic patients (experimental and comparative groups) one week after the program. The table shows that, there was a significant positive correlation between total schizophrenia quality of life and severity of auditory hallucinations of the study group and the comparative 
group (i.e. When the patients' auditory hallucinations increases the patients' quality of life score also increases) where $\mathrm{p}$ values $(0.008)$.

Table (7): Presents the correlation between levels of total schizophrenia quality of life and severity of auditory hallucinations among the studied schizophrenic patients (experimental and comparative groups) two months after the program. The table shows that, there was a no correlation between total schizophrenia quality of life and severity of auditory hallucinations for the study group.

\section{Discussion}

Schizophrenia is the most chronic psychosis in Egypt and accounts for the majority of inpatients in our psychiatric hospitals. Hallucinations are very common in patients with schizophrenia. Auditory hallucinations are one of the prominent symptoms of schizophrenia [24].

The current study revealed that, the majority of the study and compared groups schizophrenic patients were having severe auditory hallucinations in pre-program implementation. The findings could be attributed to the fact that, there is no enough stimulation to distract these voices, or there is no enough intervention provides to help the patient to decrease the severity of voices. This proved by the previous findings by Abed Elhay, (2008) the majority of schizophrenic patients reported that, as "when the voices start, that's the entire patient can hear, there's nothing else" [7]. Another study reported that between $25 \%$ and $50 \%$ of patients experience auditory hallucinations despite rigorous pharmacological treatment [5]

It was observed that, there was significant statistical difference between pre-program, after one week, after two months experimental groups as regards the severity of auditory hallucinations. This finding indicates that patients in the study group, who participated in the auditory hallucination management program, had less severity of auditory hallucination compared to schizophrenic patients in the comparison group, who received usual care. The results of this study were consistent also with Yang et al, (2015) who found that significant improvement of patients' auditory hallucinatory symptoms from pre- to post-intervention after the behavioral management program [25].

Furthermore, the results showed that auditory hallucination severity level of the study group was slightly increased at two months after the program. The researcher attributed these findings due to decreased ability to retain information and skills for a long time and continuing need for education and practice of auditory hallucinations management strategies. (Mann \& Chong, 2004), investigate the coping program in reducing psychotic symptoms and enhancing functions with schizophrenia and they found that there was a significant difference between the control and experimental groups in hallucinations, but this improvement soon relapsed to its pre-test level one month after the treatment. [26]

In this respect, In the same context, Singer\& Addington, (2009) found that, cognitive behavioral modification techniques increase adaptive behavior and reduce the frequency of hallucinations. [27] In the same line, Wkes et al, (1999) reported that significant reduction of auditory hallucination during the intervention of effective coping strategies and at 3-month follow-up. [28] According to Buccheri \& Trygstad, (2002) patients who attended the behavioral management of command hallucinations in schizophrenia perceived it as helpful and improvement was seen in the severity of auditory hallucinations. [16]

The results of the present study also revealed that there was significant statistical difference between study and control group after one week of the program, as regards total schizophrenia quality of life scores. These results mean that the auditory hallucinations management program improves psychosocial quality of life of the studied schizophrenic patients. These findings were supported by Naber et al, (2002) they found that schizophrenic patients who participate in psychosocial rehabilitation treatment for 3 months were having an improved social functioning of quality of life [29]. These results were also supported by Mankiewicz \& Turner, (2014) they were indicating that the cognitive restructuring and graded behavioral exposure for auditory hallucinations achieve a significant improvement in quality of life among schizophrenic patients [30].

The results of the current study also showed that, all of the schizophrenia quality of life domains showed significant improvement in the study group; but this effect was not seen in the control group after one week of the program. Although antipsychotic medications have proven effective in the treatment of schizophrenia patients may experience a range of adverse effects that can also negatively affect QOL [31]. This finding was confirmed when comparing the mean scores immediately post for both groups. According to El Sheshtawy, (2011) The ability to cope with symptoms and associated distress substantially contributes to QOL appraisal in schizophrenia [32].

The results of this study confirmed the beneficial effects of auditory hallucination management program on the quality of life, auditory hallucinations (i.e. When the clinical characteristics of auditory hallucinations improved, the schizophrenic quality of life also improved).

The provision of knowledge about auditory hallucinations is an important background for the patients to review their symptom experience. It was found that schizophrenic patients suffered an auditory hallucination and they had ways to manage the symptoms by themselves. The auditory hallucination management program 
The Effect of Auditory Hallucinations Management Program on Quality of Life For Schizophrenic ..

could improve the patient's quality of life through promote the patient's ability for adaptive self management of voices. The patients also learned about their voices, the impact of the voices on their lives and lifestyle. In addition the group discussions were helping the patients in evaluating and making a decision for the appropriate strategies for them

\section{Tables}

Table (1): Frequency distribution of socio-demographic data of the studied schizophrenic patients (experimental and control groups) $(\mathrm{n}=100)$

\begin{tabular}{|c|c|c|c|c|c|c|}
\hline \multirow[t]{3}{*}{ Variables } & \multicolumn{4}{|c|}{$\begin{array}{l}\text { The studied schizophrenic patients } \\
(\mathrm{n}=100)\end{array}$} & \multirow[t]{3}{*}{$\square^{2}$} & \multirow[t]{3}{*}{$\mathbf{P}$} \\
\hline & \multicolumn{2}{|c|}{$\begin{array}{l}\text { Experimental group } \\
(\mathbf{n}=50)\end{array}$} & \multicolumn{2}{|c|}{$\begin{array}{l}\text { Control group } \\
(\mathrm{n}=50)\end{array}$} & & \\
\hline & $\mathbf{n}$ & $\%$ & $\mathbf{n}$ & $\%$ & & \\
\hline \multicolumn{7}{|l|}{ Age years: } \\
\hline$<25$ & 3 & 6.0 & 3 & 6.0 & 0.047 & 0.977 \\
\hline $25-<45$ & 31 & 62.0 & 30 & 60.0 & & \\
\hline$\geq 45$ & 16 & 32.0 & 17 & 34.0 & & \\
\hline \multicolumn{7}{|l|}{ Sex: } \\
\hline Male & 25 & 50.0 & 25 & 50.0 & 0.000 & 1.000 \\
\hline Female & 25 & 50.0 & 25 & 50.0 & & \\
\hline \multicolumn{7}{|l|}{ Religion: } \\
\hline Muslim & 49 & 98.0 & 44 & 88.0 & 3.840 & 0.050 \\
\hline Christian & 1 & 2.0 & 6 & 12.0 & & \\
\hline \multicolumn{7}{|l|}{ Profession: } \\
\hline Unemployed & 19 & 38.0 & 26 & 52.0 & 3.116 & 0.211 \\
\hline Worker & 19 & 38.0 & 18 & 36.0 & & \\
\hline House keeper & 12 & 24.0 & 6 & 12.0 & & \\
\hline \multicolumn{7}{|l|}{ Education level: } \\
\hline Illiterate and read \&write & 12 & 24.0 & 6 & 12.0 & 7.325 & 0.062 \\
\hline Preparatory education. & 22 & 44.0 & 25 & 50.0 & & \\
\hline Secondary education. & 16 & 32.0 & 14 & 28.0 & & \\
\hline High education & 0 & 0 & 5 & 10.0 & & \\
\hline \multicolumn{7}{|l|}{ Marital status: } \\
\hline Single & 30 & 60.0 & 32 & 64.0 & 0.800 & 0.849 \\
\hline Married & 11 & 22.0 & 12 & 24.0 & & \\
\hline Divorced & 8 & 16.0 & 5 & 10.0 & & \\
\hline Widow & 1 & 2.0 & 1 & 2.0 & & \\
\hline \multicolumn{7}{|l|}{ Living statues: } \\
\hline Alone & 2 & 4.0 & 6 & 12.0 & 6.727 & $0.035^{*}$ \\
\hline With family & 48 & 96.0 & 40 & 80.0 & & \\
\hline With relatives & 0 & 0 & 4 & 8.0 & & \\
\hline
\end{tabular}

\section{*Significant $(\mathbf{P}<\mathbf{0 . 0 5})$}

Table (2): The clinical characteristic distribution of the studied schizophrenic patients

(study and comparative group)

\begin{tabular}{|c|c|c|c|c|c|c|}
\hline \multirow[t]{3}{*}{ Variables } & \multicolumn{4}{|c|}{$\begin{array}{l}\text { The studied schizophrenic patients } \\
(\mathrm{n}=100)\end{array}$} & \multirow[t]{3}{*}{$\square^{2}$} & \multirow[t]{3}{*}{$\mathbf{P}$} \\
\hline & \multicolumn{2}{|c|}{$\begin{array}{l}\text { Experimental group } \\
(\mathbf{n = 5 0 )}\end{array}$} & \multicolumn{2}{|c|}{$\begin{array}{l}\text { Comparative group } \\
(\mathbf{n}=\mathbf{5 0})\end{array}$} & & \\
\hline & $\mathbf{n}$ & $\%$ & $\mathbf{n}$ & $\%$ & & \\
\hline \multicolumn{7}{|l|}{ Age of onset of disease: } \\
\hline$<20$ & 10 & 20.0 & 12 & 24.0 & 7.250 & 0.123 \\
\hline $20-<25$ & 21 & 42.0 & 22 & 44.0 & & \\
\hline $25-<30$ & 8 & 16.0 & 11 & 22.0 & & \\
\hline $30-<35$ & 11 & 22.0 & 3 & 6.0 & & \\
\hline$\geq 35$ & 0 & 0 & 2 & 4.0 & & \\
\hline \multicolumn{7}{|l|}{ No. of hospital admission: } \\
\hline 1 & 3 & 6.0 & 1 & 2.0 & 1.167 & 0.558 \\
\hline $2-3$ & 11 & 22.0 & 13 & 26.0 & & \\
\hline $4 \&$ more & 36 & 72.0 & 36 & 72.0 & & \\
\hline \multicolumn{7}{|l|}{$\begin{array}{l}\text { Length of hospital admission } \\
\text { (months): }\end{array}$} \\
\hline$<3$ & 38 & 76.0 & 29 & 58.0 & 3.909 & 0.271 \\
\hline $3-<6$ & 6 & 12.0 & 9 & 18.0 & & \\
\hline $6-<12$ & 3 & 6.0 & 5 & 10.0 & & \\
\hline$\geq 12$ & 3 & 6.0 & 7 & 14.0 & & \\
\hline $\begin{array}{l}\text { Years since onset of auditory } \\
\text { hallucinations: }\end{array}$ & & & & & & \\
\hline
\end{tabular}


The Effect of Auditory Hallucinations Management Program on Quality of Life For Schizophrenic ..

\begin{tabular}{|l|l|l|l|l|l|l|}
\hline$<5$ & 7 & 14.0 & 3 & 6.0 & 3.038 & 0.219 \\
\hline $5-<10$ & 7 & 14.0 & 4 & 8.0 & & \\
\hline$\geq 10$ & 36 & 72.0 & 43 & 86.0 & & \\
\hline $\begin{array}{l}\# \text { Reaction to auditory } \\
\text { hallucinations: }\end{array}$ & & & & & & \\
\hline Fear & 17 & 34.0 & 15 & 30.0 & 0.184 & 0.668 \\
\hline Happy & 3 & 6.0 & 4 & 8.0 & 0.154 & 0.695 \\
\hline Upset/sad & 32 & 64.0 & 31 & 62.0 & 0.043 & 0.836 \\
\hline Angry & 2 & 4.0 & 13 & 26.0 & 9.490 & $0.002 *$ \\
\hline Anxiety & 7 & 14.0 & 4 & 8.0 & 0.919 & 0.338 \\
\hline Terror & 9 & 18.0 & 6 & 12.0 & 0.706 & 0.401 \\
\hline Confused & 1 & 2.0 & 1 & 2.0 & 0.000 & 1.000 \\
\hline Depressed & 9 & 18.0 & 6 & 12.0 & 0.706 & 0.401 \\
\hline Helpless & 3 & 60.0 & 2 & 4.0 & 0.211 & 0.646 \\
\hline Hopeless & 3.0 & 2 & 4.0 & 0.211 & 0.646 \\
\hline $\begin{array}{l}\text { Anxious before auditory } \\
\text { hallucinations: }\end{array}$ & & & & & & \\
\hline No & 0 & 0 & 1 & 2.0 & 1.010 & 0.315 \\
\hline Yes & 50 & 100 & 49 & 98.0 & & \\
\hline
\end{tabular}

*Significant $(\mathbf{P}<\mathbf{0 . 0 5})$

\#More than one item was chosen for patient's reaction toward auditory hallucinations

Table (3): Mean scores and severity of auditory hallucinations among the studied schizophrenic patients (experimental and control groups) $(\mathrm{n}=100)$.

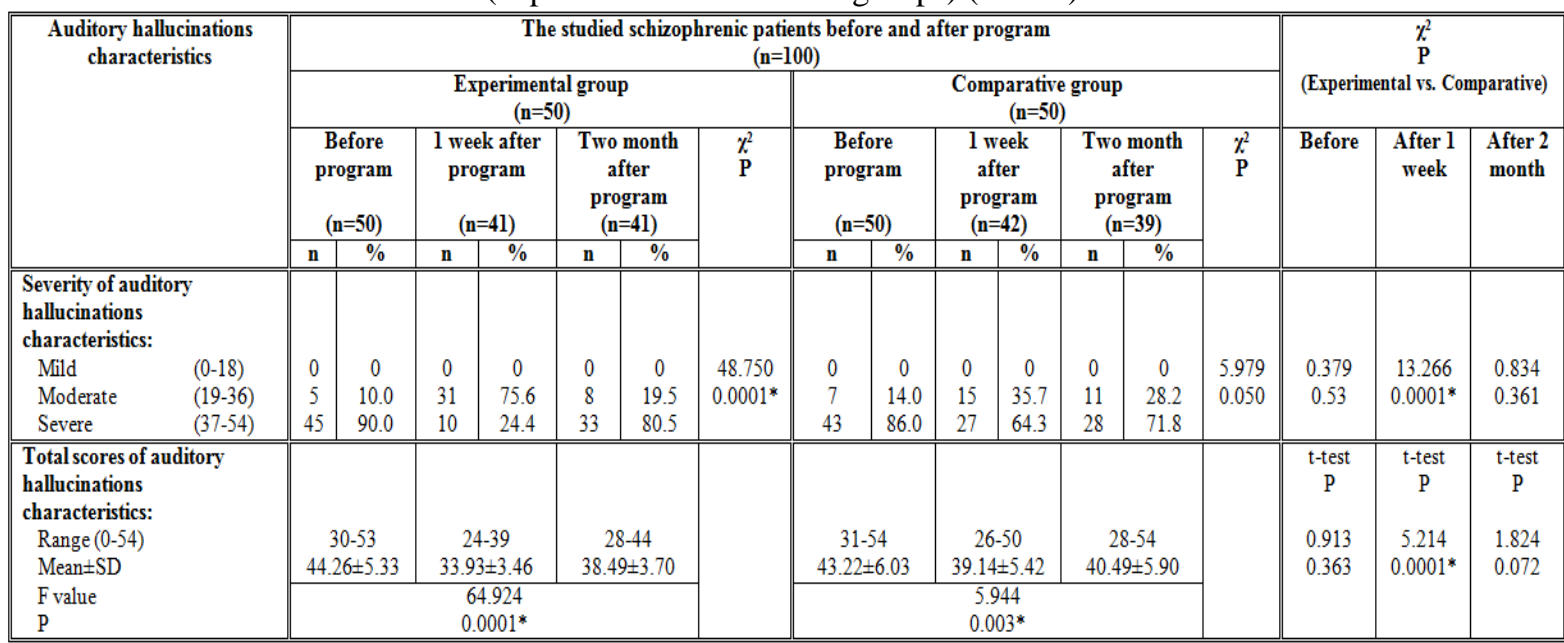

\section{*Significant $(\mathbf{P}<\mathbf{0 . 0 5})$}

Table (4): Mean scores of schizophrenia quality of life domains and total among the studied schizophrenic patients (experimental and Comparative groups) $(n=100)$.

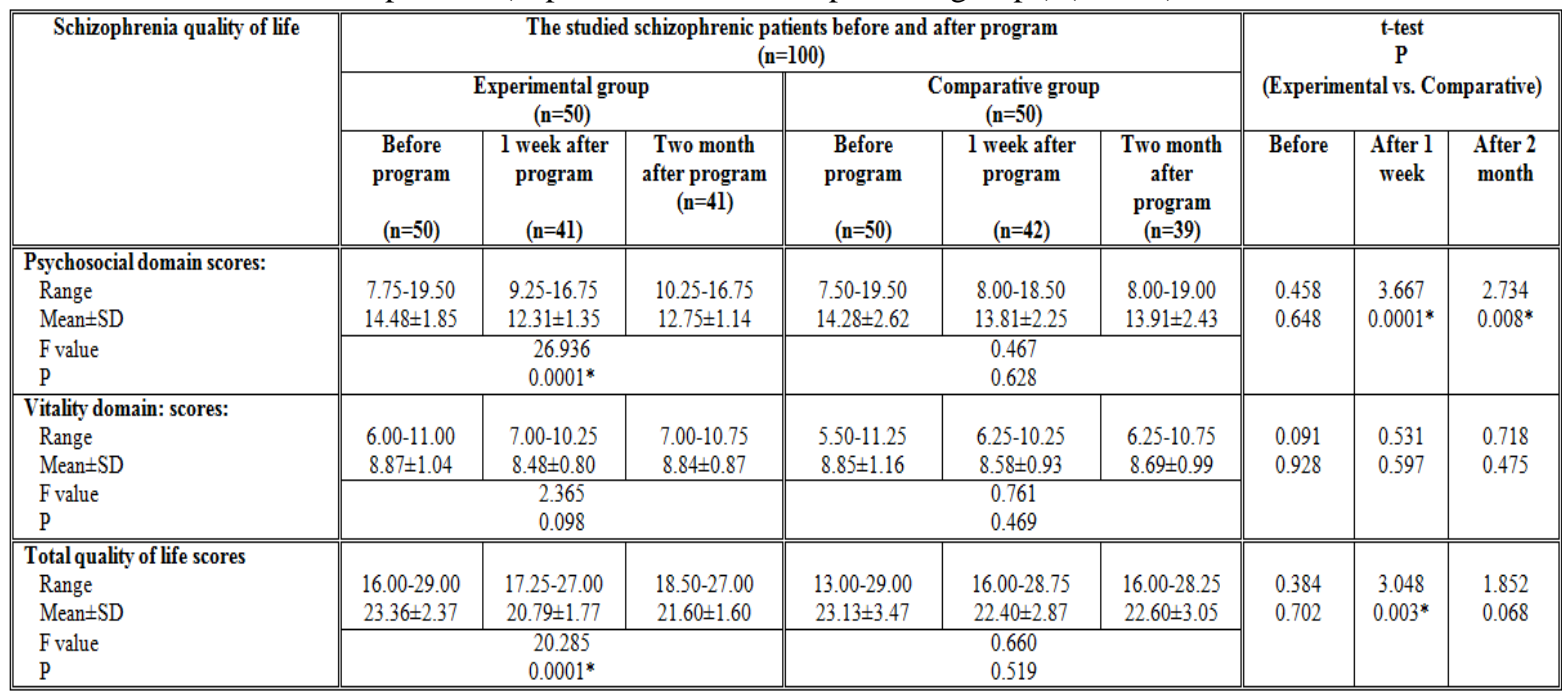

*Significant $(\mathbf{P}<\mathbf{0 . 0 5})$ 
The Effect of Auditory Hallucinations Management Program on Quality of Life For Schizophrenic ..

Table (5): Levels of schizophrenia quality of life domains and total among the studied schizophrenic patients (experimental and Comparative groups) $(\mathrm{n}=100)$.

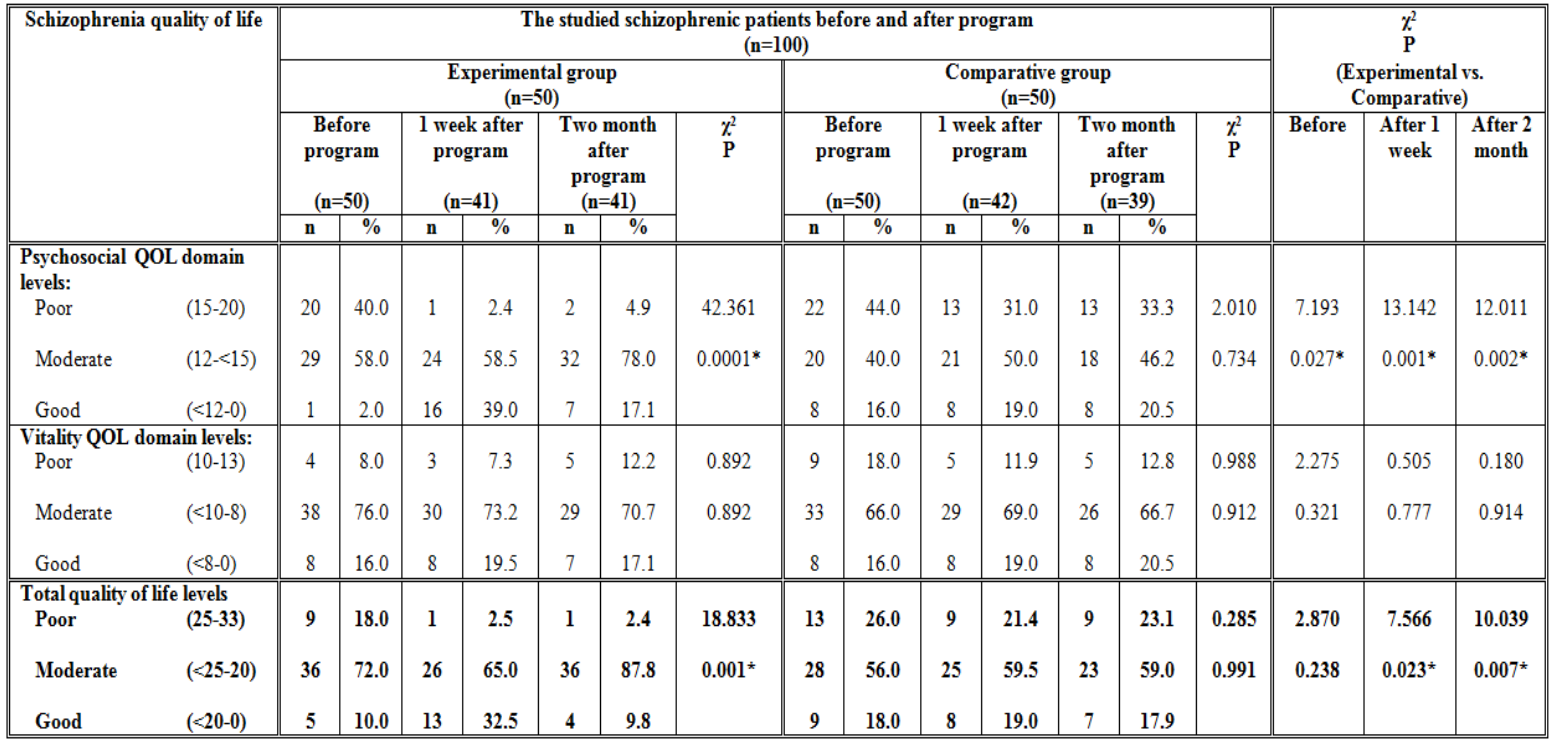

\section{*Significant $(\mathbf{P}<0.05)$}

Table (6): Relationship between levels of total schizophrenia quality of life and severity of total auditory hallucinations, total anxiety and total depression among the studied schizophrenic patients (experimental and control groups) one week after program $(\mathrm{n}=100)$.

\begin{tabular}{|c|c|c|c|c|c|c|c|c|c|c|c|c|c|c|c|c|c|}
\hline \multirow[t]{4}{*}{ Variables } & \multicolumn{14}{|c|}{$\begin{array}{l}\text { Levels of total schizophrenia quality of life among the studied schizophrenic patients one week after program } \\
\qquad(\mathrm{n}=100)\end{array}$} & \multirow{2}{*}{\multicolumn{3}{|c|}{$\begin{array}{c}\varkappa^{2} \\
\mathrm{P} \\
\text { (Experimental vs. Comparative) }\end{array}$}} \\
\hline & \multicolumn{7}{|c|}{$\begin{array}{c}\text { Experimental group } \\
(\mathrm{n}=50)\end{array}$} & \multicolumn{7}{|c|}{$\begin{array}{l}\text { Comparative group } \\
(\mathrm{n}=50)\end{array}$} & & & \\
\hline & \multicolumn{2}{|c|}{$\begin{array}{l}\text { Poor } \\
(\mathrm{n}=1)\end{array}$} & \multicolumn{2}{|c|}{$\begin{array}{l}\text { Moderate } \\
(\mathrm{n}=26)\end{array}$} & \multicolumn{2}{|c|}{$\begin{array}{c}\text { Good } \\
(n=13)\end{array}$} & \multirow[t]{2}{*}{$\chi_{\mathrm{P}}^{2}$} & \multicolumn{2}{|c|}{$\begin{array}{l}\text { Poor } \\
(\mathrm{n}=9)\end{array}$} & \multicolumn{2}{|c|}{$\begin{array}{c}\text { Moderate } \\
(\mathrm{n}=\mathbf{2 5})\end{array}$} & \multicolumn{2}{|c|}{$\begin{array}{l}\text { Good } \\
(n=8)\end{array}$} & \multirow[t]{2}{*}{$\chi_{\mathrm{P}}^{2}$} & \multirow[t]{2}{*}{ Before } & \multirow[t]{2}{*}{$\begin{array}{c}\text { After l } \\
\text { week }\end{array}$} & \multirow[t]{2}{*}{$\begin{array}{l}\text { After } 1 \\
\text { month }\end{array}$} \\
\hline & $\mathrm{n}$ & $\%$ & $\mathbf{n}$ & $\%$ & $\mathrm{n}$ & $\%$ & & $\mathrm{n}$ & $\%$ & $\mathrm{n}$ & $\%$ & $\mathbf{n}$ & $\%$ & & & & \\
\hline $\begin{array}{l}\text { Severity of auditory } \\
\text { hallucinations characteristics: }\end{array}$ & & & & & & & & & & & & & & & & & \\
\hline Mild & 0 & 0 & 0 & 0 & 0 & 0 & 5.538 & 0 & 0 & 0 & 0 & 0 & 0 & 4.804 & 0.050 & 7.100 & 7.290 \\
\hline Moderate & 0 & 0 & 18 & 60.0 & 12 & 40.0 & 0.063 & 6 & 40.0 & 7 & 46.7 & 2 & 13.3 & 0.091 & 0.830 & $0.008^{*}$ & $0.007^{*}$ \\
\hline Severe & 1 & 10.0 & 8 & 80.0 & 1 & 10.0 & & 3 & 11.1 & 18 & 66.7 & 6 & 22.2 & & & & \\
\hline
\end{tabular}

*Significant $(\mathbf{P}<0.05)$

Table (7): Relationship between levels of total schizophrenia quality of life and severity of total auditory hallucinations, total anxiety and total depression among the studied schizophrenic patients (experimental and Comparative groups) one month after program $(n=100)$.

\begin{tabular}{|c|c|c|c|c|c|c|c|c|c|c|c|c|c|c|c|c|c|}
\hline \multirow[t]{4}{*}{ Variables } & \multicolumn{14}{|c|}{$\begin{array}{l}\text { Levels of total schizophrenia quality of life among the studied schizophrenic patients two month after program } \\
\qquad(\mathrm{n}=100)\end{array}$} & \multirow{2}{*}{\multicolumn{3}{|c|}{$\begin{array}{c}\chi^{2} \\
\mathrm{P} \\
\text { (Experimental vs. Comparative) }\end{array}$}} \\
\hline & \multicolumn{7}{|c|}{$\begin{array}{l}\text { Experimental group } \\
(\mathrm{n}=50)\end{array}$} & \multicolumn{7}{|c|}{$\begin{array}{l}\text { Comparative group } \\
(\mathrm{n}=50)\end{array}$} & & & \\
\hline & \multicolumn{2}{|c|}{$\begin{array}{l}\text { Poor } \\
(\mathrm{n}=\mathrm{l})\end{array}$} & \multicolumn{2}{|c|}{$\begin{array}{c}\text { Moderate } \\
(\mathrm{n}=36)\end{array}$} & \multicolumn{2}{|c|}{$\begin{array}{l}\text { Good } \\
(\mathrm{n}=4)\end{array}$} & \multirow[t]{2}{*}{$\begin{array}{l}\psi^{2} \\
\mathrm{P}\end{array}$} & \multicolumn{2}{|c|}{$\begin{array}{l}\text { Poor } \\
(\mathrm{n}=9)\end{array}$} & \multicolumn{2}{|c|}{$\begin{array}{c}\text { Moderate } \\
(\mathrm{n}=23)\end{array}$} & \multicolumn{2}{|c|}{$\begin{array}{l}\text { Good } \\
(\mathrm{n}=7)\end{array}$} & \multirow[t]{2}{*}{$\begin{array}{l}\psi^{2} \\
\mathrm{P}\end{array}$} & \multirow[t]{2}{*}{ Before } & \multirow[t]{2}{*}{$\begin{array}{c}\text { After l } \\
\text { week }\end{array}$} & \multirow[t]{2}{*}{$\begin{array}{c}\text { After l } \\
\text { month }\end{array}$} \\
\hline & $\mathbf{n}$ & $\%$ & n & $\%$ & $\mathbf{n}$ & $\%$ & & $\mathrm{n}$ & $\%$ & $\mathrm{n}$ & $\%$ & $\mathbf{n}$ & $\%$ & & & & \\
\hline $\begin{array}{l}\text { Severity of auditory } \\
\text { hallucinations characteristics: }\end{array}$ & & & & & & & & & & & & & & & & & \\
\hline Mild & 0 & 0 & 0 & 0 & 0 & 0 & 1.380 & 0 & 0 & 0 & 0 & 0 & 0 & 4.653 & 1.110 & 0.010 & 0.140 \\
\hline Moderate & 0 & 0 & 8 & 100 & 0 & 0 & 0.501 & 5 & 45.5 & 4 & 36.4 & 2 & 18.2 & 0.098 & 0.292 & 0.906 & 0.712 \\
\hline Severe & 1 & 3.0 & 28 & 84.8 & 4 & 12.1 & & 4 & 14.3 & 19 & 67.9 & 5 & 17.9 & & & & \\
\hline
\end{tabular}

*Significant $(\mathbf{P}<\mathbf{0 . 0 5})$

\section{Conclusion}

Based on the results of the present study it can be concluded that, the results of this study clearly show that the auditory hallucination management program were effective for schizophrenic patients, and demonstrated decrease in the severity level of auditory hallucination, improvement the schizophrenic quality of life in comparison before the program and also presented less severity of auditory hallucinations, improving the schizophrenic quality of life in comparison with the patients receiving usual care from hospital. 
In the light of the results of the present study, it could be recommended that:

1. The auditory hallucination management program should be recommended as a nursing intervention program for schizophrenic patients.

2. All schizophrenic patients who had auditory hallucinations should be counseled and encouraged to participate in auditory hallucinations management program at the time of diagnosis to reduce the severity of auditory hallucinations and improve quality of life.

3. Psychiatric health care provider (psychiatric nurse and/or psychiatrist) should provide accurate information to schizophrenic patients who have auditory hallucinations about different auditory hallucinations management techniques used by other hallucinating patients, and they reported efficacy, to encourage further self discovery of personally effective symptom management techniques.

\section{Limitation}

This research is the first step of an auditory hallucination management program development. The reduction of the characteristics and severity of auditory hallucination found in this study may result from medical treatments also, which the patients had been receiving continuously. These possible effects were not taken into account of the result of this study.

\section{References}

[1]. NIMH, 2011), National Institute of Mental Health (NIMH, 2011). Schizophrenia. Retrieved May 20, 2011, from http://www.nimh.nih.gov/health/publications/schizophrenia/complete-indx.shtml Nilsson, L.-L.,

[2]. Bagul, A. C. (2012). " effect of coping strategies on chronic drug resistant auditory hallucination in schizophrenia : a cross over study”. The Indian Journal of Occupational Therapy, 44 (1), 20-29.

[3]. Halter, M.J. (2014). Varcarolis' foundation of psychiatric mental health nursing : a clinical approach. (7th ed.). St. Louis, MO: Saunders/Elsevier.

[4]. Woodruff, P. W. R. (2004). Auditory hallucinations: insights and questions from neuro-imaging. Cognitive Neuropsychiatry, 9 , 73-9210.1080/13546800344000165 [PubMed] [Cross Ref]

[5]. HW So, S. \& Wong, C.W. (2008). Experience and coping with auditory hallucinations in first-episode psychosis : Relationship with stress coping, (5). Hong kong journal of psychiatry, 5(18):115-21

[6]. Carter, D.M., Mackinnon, A. \& Copolov, D.L. (1996). Patients's strategies for coping with auditory hallucinations. Journal of Nervous and Mental Disease, 184, 159-164

[7]. Abd Elhay, E. S. (2008). Self management of auditory hallucination among schizophrenic inpatients. Published Master Thesis. Faculty of Nursing. Alexandria University- Egypt

[8]. American Psychiatric Association (APA). (1997). Diagnostic and statistical manual of mental disorders. American Psychiatric Association (APA): Washington, DC: American Psychiatric Association

[9]. Wilkinson, G., Hesdon, B., Wild, D., Cookson, R., Farina, C., Sharma, V., Fitzpatrick, R., \& Jenkinson, C., (2000). Selfreport quality of life measure for people with schizophrenia: the SQLS. British Journal of Psychiatry, 177, 42-46

[10]. Awad, AG, Voruganti, LNP. (2000). Intervention research in psychosis: issues related to the assessment of quality of life. Schizophrenia Bull; 26: 557-64.

[11]. Badan Bâ. M. (2008). Auditory hallucinations and quality of life of psychotic patients. Schizophrenia Research (2)102/1-3

[12]. Alshowkan, A., Curtis, J, White, Y. (2015). Factors Affecting the Quality of Life for People with Schizophrenia in Saudi Arabia: A Qualitative Study. Journal of Psychiatry, 18: 295 doi: 10.4172/2378-5756.1000295

[13]. Tsai, Y. F., \& Ku, Y. C. (2005). Self-care symptom management strategies for auditory hallucinations among inpatients with schizophrenia at a veterans' hospital in Taiwan. Archives of Psychiatric Nursing, 19(4), 194-199. http://doi.org/10.1016/j.apnu.2005.05.005

[14]. Kanungpairn, T., Sitthimongkol, Y., Wattanapailin, A., \& Klainin, P. (2007). Effects of a symptom management program on auditory hallucinations in Thai outpatients with a diagnosis of schizophrenia: A pilot study. Nursing and Health Sciences, 9, 34-39. http://doi.org/10.1111/j.1442-2018.2007.00302.x

[15]. Buffum, M. D., Buccheri, R. K., \& Trygstad, L. N. (2014). Dissemination of 10-Session Behavioral Management of Auditory Hallucinations Course in Mental Health Outpatient Settings. Journal of Psychosocial nursing . 52, (4),15-23

[16]. Buccheri, R. K., Trygstad, L. N., Buffum, M. D., Birmingham, P., \& Dowling, G. A. (2013). Self-Management of Unpleasant Auditory Hallucinations A Tested Practice Model. Journal of Psychosocial Nursing and Mental Health Services, 51(11), 26-34. http://doi.org/10.3928/02793695-20130731-02

[17]. Trygstad, L., Buccheri, R., Dowling, G., Zind, R., White, K., Griffin, J. J. \& Hebert, P. (2002). Behavioral management of persistent auditory hallucinations in schizophrenia: Outcomes from a 10-week course. Journal of the American Psychiatric Nurses Association, 8(3), 84-91. http://doi.org/10.1067/mpn.2002.125223

[18]. Linder, L. (2010). Analysis of the UCSF Symptom Management Theory: Implications for Pediatric Oncology Nursing. Journal of Pediatric Oncology Nursing, 27(6), 316-324. http://doi.org/10.1177/1043454210368532

[19]. Chen, W.-C., Chu, H., Lu, R.-B., Chou, Y.-H., Chen, C.-H., Chang, Y.-C., Chou, K.-R. (2009). Efficacy of progressive muscle relaxation training in reducing anxiety in patients with acute schizophrenia. Journal of Clinical Nursing, 18(15), 2187-2196. http://doi.org/10.1111/j.1365-2702.2008.02773.x

[20]. Buccheri, R. K., Trygstad, L. N., Buffum, M. D., Lyttle, K., \& Dowling, G. (2010). Comprehensive evidence-based program teaching self-management of auditory hallucinations on inpatient psychiatric units. Issues in Mental Health Nursing, 31(3), 223231. http://doi.org/10.3109/01612840903288568

[21]. Dodd, M., Janson, S., Facione, N., Faucett, J., Froelicher, E. S., Humphreys, J., Taylor, D. (2001). Advancing the science of symptom management. Journal of Advanced Nursing, 33(5), 668-676. http://doi.org/10.1046/j.1365-2648.2001.01697.x

[22]. Oulis P, Gournellis R, Konstantakopoulos G, Matsoukas T , Micalopoulou P. G, Soldatos C,\& Lykouras L .(2007). Clinical dimensions of auditory hallucinations in schizophrenic disorders. Comprehensive psychiatry, 48:337-342

[23]. Kuo, P.J, Chen-Sea, M.J, Lu, R.B.( 2007). Validation of the Chinese version of the Schizophrenia Quality of Life Scale Revision 4 (SQLS-R4) in Taiwanese patients with schizophrenia. Quality Life Research, 16:1533-8. 
The Effect of Auditory Hallucinations Management Program on Quality of Life For Schizophrenic ..

[24]. Daalman, K., Verkooijen, S., Derks, E. M., Aleman, A., \& Sommer, I. E. C. (2012). The influence of semantic top-down processing in auditory verbal hallucinations. Schizophrenia Research, 139(1-3), 82-86. http://doi.org/10.1016/j.schres.2012.06.005

[25]. Yang, C.-Y., Lee, T.-H., Lo, S.-C., \& Beckstead, J. W. (2015). The effects of auditory hallucination symptom management programme for people with schizophrenia: a quasi-experimental design. Journal of Advanced Nursing, 71(12), $2886-2897$. http://doi.org/10.1111/jan.12754

[26]. Mann S, Chong B (2004). The effect of symptoms coping program in reducing psychotic symptoms and enhancing functions in Chinese with schizophrenia. American Journal of Psychiatric Rehabilitation, 7: 69-82.

[27]. Singer, A. R., \& Addington, D. E. (2009). The Application of Cognitive Therapy for Command Hallucinations. Cognitive and Behavioral Practice, 16(1), 73-83. http://doi.org/10.1016/j.cbpra.2008.03.003

[28]. Wkes, T., Parr, A.M., Landau, S. (1999). Group treatment of auditory hallucinations, (8 );175:180-5.

[29]. Naber, D., Karow, A., \& Lambert, M. (2002). Psychosocial outcomes in patients with schizophrenia: Quality of life and reintegration. Current Opinion in Psychiatry, 15(1),31-36. http://doi.org/10.1097/00001504-200201000-00006

[30]. Mankiewicz, P. D., \& Turner, C. (2014). Cognitive restructuring and graded behavioral exposure for delusional appraisals of auditory hallucinations and co-morbid anxiety in paranoid schizophrenia. Case Reports in Psychiatry,12, (4) 564. http://doi.org/10.1155/2014/124564

[31]. Awad, A. G., \& Voruganti, L. N. (2012). Measuring quality of life in patients with schizophrenia: an update. Pharmacoeconomics, 30(3), 183-195. http://doi.org/10.2165/11594470-000000000-00000

[32]. El Sheshtawy, E. A. M. (2011). Coping with stress and quality of life in schizophrenic patients. Asian Journal of Psychiatry, 4(1), 51-4. http://doi.org/10.1016/j.ajp.2010.09.003 